\title{
Simulasi Sistem Otomasi Load Shedding menggunakan Prediksi Beban
}

\section{ERWANI MERRY SARTIKA, RUDI SARJONO, REINALDO STEVEN RESTIANTO}

Program Studi Teknik Elektro Universitas Kristen Maranatha

Email: erwani.ms@eng.maranatha.edu

Received 27 September 2018 | Revised 23 Oktober 2018| Accepted 7 Januari 2019

\begin{abstract}
ABSTRAK
Simulator penggunaan energi listrik sangat membantu dalam perencanaan pasokan listrik secara terus menerus atau perlu pemadaman bila terjadi gangguan. Agar kinerja pembangkit dapat kembali normal, bertahap, dan terencana akibat mengalami gangguan, maka digunakan metoda Load Shedding. Sistem otomasi dibutuhkan untuk merealisasikan metoda Load Shedding, dan melalui simulator dapat mengurangi resiko terhadap kerusakan bila langsung diimplementasikan. PLC digunakan untuk memprediksi beban saat load shedding, sedangkan SCADA digunakan untuk menampilkan prioritas dan status beban. Load shedding 1 adalah tindakan pelepasan beban bila pada salah satu genset mengalami gangguan, sedangkan Load shedding 2 bila pada kedua genset mengalami gangguan. Simulasi sistem load shedding 1 dan 2 berhasil dilakukan pelepasan beban secara otomatis. Setelah pelepasan beban, kapasitas beban yang ditanggung genset sesuai dengan prediksi dari PLC. Terdapat perbedaan hasil antara daya yang diprediksi secara perhitungan dan daya terukur, kemungkinan disebabkan beban masih belum steady saat data diambil.
\end{abstract}

Kata kunci: Otomasi, Simulator, Sistem Load shedding, SCADA, PLC

\section{ABSTRACT}

Simulator of the use of electrical energy is very helpful in planning electricity supply continuously or needs to be suppressed if a disturbance occurs. In order for the generator performance to return to normal, gradual, and planned due to interference, the Load Shedding method is used. Automation systems are needed to realize the Load Shedding method, and through simulators can reduce the risk of damage if implemented immediately. PLC was used to predict load during load shedding, while SCADA was used to display priority and load status. Load shedding 1 was a load release action if one of the generator sets was disrupted, while Load shedding 2 if in both gensets were disrupted. Load system simulation of shedding 1 and 2 was successfully released by load automatically. After the load was released, the load capacity borne by the generator was in accordance with the predictions of the PLC., the load capacity borne by the generator was in accordance with the predictions of the PLC. There was a difference in results between the predicted power and measured power, possibly because the load was still not steady when the data was taken.

Keywords: Automation, Simulator, Load Shedding System, SCADA, PLC 


\section{PENDAHULUAN}

Kebutuhan energi listrik dalam kehidupan merupakan bagian yang utama, tidak hanya di lingkungan rumah tangga, bahkan semakin meningkat kebutuhannya seiring dengan perkembangan teknologi dan pembangunan (Wang, Guo, Wu, Liu, \& Zhou, 2014). Simulator penggunaan energi listrik sangat membantu dalam perencanaan pasokan listrik. Perencanaan listrik dalam bentuk simulator memungkinkan untuk mensimulasikan pasokan listrik secara terus menerus atau perlu pemadaman bila terjadi gangguan (Sartika \& Indra Maulidin, 2018). Perubahan beban secara tiba-tiba merupakan salah satu gangguannya. Oleh karena itu untuk sumber pasokan listrik yang terbatas, satu-satunya tindakan yang harus dilakukan yaitu dengan melakukan pelepasan beban (load shedding) (Wang, Guo, Wu, Liu, \& Zhou, 2014).

Load shedding dalam bahasa Indonesia adalah pelepasan beban. Pelepasan beban yang dimaksud bukan istilah dalam sistem informasi namun istilah dalalm kelistrikan, yaitu metode pelepasan beban untuk menyeimbangkan beban agar kinerja pembangkit menjadi optimal, dengan cara bertahap dan terencana. Pengelompokan beban dilakukan agar saat sistem load shedding sedang berlangsung, beban dilepas secara bertahap sehingga pembangkit mampu untuk memenuhi kebutuhan pasokan listrik yang dibutuhkan. Semakin tinggi tahapan pada load shedding, semakin tinggi pula prioritas beban tersebut (Gusaebi, 2014). Implementasi dari sistem load shedding sudah dipakai oleh beberapa perusahaan besar contohnya adalah PT. PLN, PT. Pertamina EP, dan perusahaan lainnya(Gusaebi, 2014).

Perkembangan teknologi yang pesat membuat adanya tuntutan baru dalam dunia industri yaitu industri harus dapat bekerja lebih cepat, tepat, dan optimal. Tuntutan tersebut tidak dapat dicapai apabila hanya mengandalkan kemampuan sistem yang manual dan menggantungkan produksi dari kerja sumber daya manusia yang memiliki keterbatasan. Oleh karena itu otomasi sangat dibutuhkan untuk membantu memenuhi tuntutan tersebut. Otomasi adalah pemanfaat sistem kontrol seperti halnya komputer yang digunakan mengendalikan mesin-mesin industri dan kontrol proses untuk menggantikan operator tenaga manusia (Agus Putranto, Abdul Mukti 2008)(Wahyudi, Abdurahman, 2017).

Untuk membuat otomasi pada suatu sistem secara langsung membutuhkan biaya yang sangat besar dan memiliki resiko yang tinggi terhadap kerusakan. Oleh karena itu dibutuhkan simulator sebelum mengimplementasikan otomasi pada suatu sistem untuk menurunkan resiko kerusakan pada alat yang digunakan (Sartika \& Indra Maulidin, 2018). Selain itu dengan simulator, sistem tersebut dapat dikembangkan lebih lanjut tanpa harus mencoba pada sistem secara langsung (Nugraheni \& Setiabudy, 2014).

Berbagai pembahasan mengenai Load shedding umumnya berupa proses perhitungan pelepasan beban (Ye, Baohui, \& Member, 2014)(Keles, Alagoz, \& Kaygusuz, 2015) diantaranya adalah mengusulkan pendekatan perhitungan pelepasan beban minimum baru berdasarkan teori optimisasi multi objektif dengan mempertimbangkan perbedaan beban dan memperkenalkan faktor penting untuk menggambarkan perbedaan tersebut. Pendekatan ini memotong beban yang kurang penting dan mencoba untuk mendapatkan jumlah total 
pelepasan beban minimum dalam proses pelepasan beban (Wang, Guo, Wu, Liu, \& Zhou, 2014). Selain itu terdapat pula yang mengusulkan dua strategi yang ditingkatkan berdasarkan pada strategi kontrol beban yang biasa dengan mempertimbangkan fluktuasi dan karakteristik korelasi dari keluaran daya generasi terdistribusi yang terbarukan dan permintaan beban (Guan \& Wang, 2016).

Namun realisasi simulator sistem otomasi Load shedding belum pernah dibuat sebagai perencanaan pasokan listrik bila terjadi gangguan. Melalui otomasi pada simulator sistem load shedding yang dibuat, simulasi dapat dilakukan secara langsung sehingga cara kerja sistem load shedding dapat ditunjukkan. Metode yang digunakan mulai dari perhitungan impedansi seluruh beban terlebih dahulu, pemilihan prioritas beban bila terjadi load shedding, dan sistem otomatis memprediksi beban yang akan dimatikan. Metode ini dirancang agar mempermudah memahami cara kerja sistem load shedding.

Pada paper ini akan menjelaskan proses otomasi pada simulator sistem load shedding yang dikendalikan dengan PLC (Programmable Logic Controller). PLC digunakan untuk memprediksi beban yang dimatikan saat terjadi load shedding sesuai dengan kondisi load shedding dan juga melakukan tindakan load shedding.

\section{PERANCANGAN METODE SISTEM LOAD SHEDDING}

\subsection{Load Shedding}

Load Shedding adalah suatu bentuk tindakan pelepasan beban yang terjadi untuk mengamankan operasi unit pembangkit dari kemungkinan terjadinya padam total. Hal ini disebabkan oleh adanya beban lebih yang ditanggung pembangkit sehingga untuk mengembalikan kondisi menjadi seperti semula diperlukan pelepasan pada beberapa beban tertentu. Tujuan utama dari load shedding adalah untuk mengantisipasi dan mencegah pasokan listrik padam total karena disebabkan oleh pembangkit yang kelebihan beban. Kelebihan beban ini sering disebabkan adanya pembangkit yang tidak aktif secara tiba - tiba, gangguan pada saluran transimisi, dan juga gangguan dari pembangkit pembangkit itu sendiri.

Akibat dari kelebihan beban dapat mengganggu kestablian sistem yang dapat menimbulkan beberapa masalah antara lain yaitu penurunan tegangan dan penurunan frekuensi. Oleh karena itu strategi dari pelepasan beban ini telah diimplementasikan di sistem Jawa - Bali. Strategi pelepasan beban ini terdiri dari pengurangan beban secara manual load shedding dan automatic load shedding. Pelepasan beban dibedakan menjadi 2 macam yaitu :

1. Pelepasan Beban Manual (Manual Load Shedding)(Gusaebi, 2014)

Manual load shedding adalah skema pelepasan beban yang hanya digunakan dalam keadaan tidak begitu penting atau saat control load shedding tidak bekerja dalam keadaan normal. Kekurangan dari cara pelepasan ini yaitu harus mempekerjakan tenaga operator yang banyak, beban yang dilepas kadang melebihi kebutuhan beban yang harus dilepas, dan adanya faktor keterlambatan dalam tindakan operator. 


\section{Pelepasan Beban Otomatis (Automatic Load Shedding)(Gusaebi, 2014)}

Automatic load shedding adalah skema pelepasan beban secara otomatis yang bertujuan untuk menyeimbangkan daya beban dan kapasitas pembangkit dalam kondisi darurat. Kondisi darurat yang dimaksud seperti adanya pembangkit yang tidak aktif secara tiba - tiba dan menyebabkan daya beban akan lebih besar daripada kapasitas pembangkit. Kelebihan dari cara pelepasan ini yaitu tidak memerlukan banyak operator dan mengurangi tindakan lambat dari operator.

\subsection{Sistem Load Shedding yang dirancang}

Pada sistem load shedding yang dirancang, akan dilakukan perhitungan impedansi seluruh beban terlebih dahulu, selanjutnya pengguna dapat menentukan prioritas beban bila terjadi load shedding sehingga simulator menggunakan PLC sebagai pengontrol dapat secara otomatis memprediksi beban yang akan dimatikan. Metode ini dirancang agar mempermudah memahami cara kerja simulator sistem load shedding.

Load shedding 1 adalah tindakan pelepasan beban yang dilakukan bila pada salah satu genset mengalami gangguan berupa alarm. Dalam tindakan pelepasan beban ini yang diperhatikan adalah daya dari masing - masing beban. Beban yang dilepas dalam load sheding 1 adalah beban dengan daya semu terbesar dan bukan beban prioritas utama.

Sedangkan load shedding 2 adalah tindakan pelepasan beban yang dilakukan bila pada kedua genset mengalami gangguan (bisa berupa alarm/trip). Dalam tindakan pelepasan beban ini yang diperhatikan adalah kapasitas maksimum daya beban yang dapat ditanggung genset yaitu 1200 VA. Dalam pelepasan beban tersebut harus dilakukan secara bertahap dari beban yang memiliki prioritas paling rendah.

Untuk mendapatkan prediksi beban yang dilepas maka perlu dilakukan perhitungan daya dari masing-masing beban. Untuk mendapatkan daya dari masing-masing dari beban adalah dengan menggunakan Persamaan (1) untuk menghitung daya nyata, Persamaan (2) untuk menghitung daya reaktifdan Persamaan (3) untuk menghitung daya semu (Belly, Agusman, \& Lukman, 2010).

$$
\begin{aligned}
& P=\frac{V^{2}}{Z} \cos \theta \\
& Q=\frac{V^{2}}{Z} \sin \theta \\
& S=\frac{V^{2}}{Z}
\end{aligned}
$$

$\mathbf{Z}=$ Impedansi beban

$\mathrm{V}=$ Tegangan

$P$ = Daya nyata

$\mathrm{Q}=$ Daya reaktif

$\mathrm{S}$ = Daya semu

$\theta=$ Selisih sudut antara tegangan dan arus / beban 
Untuk mendapatkan impedansi dari masing-masing beban adalah dengan menggunakan Persamaan (4) untuk menghitung impedansi beban. Sedangkan dengan menggunakan Persamaan (5) untuk menghitung sudut beban (Belly et al., 2010).

$$
\begin{gathered}
Z=\frac{V^{2}}{S} \\
\theta=\sin \square^{-1}\left(\frac{Q}{V I}\right)
\end{gathered}
$$

$\mathrm{Z}$ = Impedansi beban

$\mathrm{V}$ = Tegangan

$\mathrm{I}=$ Arus

$\mathrm{Q}=$ Daya reaktif

$\mathrm{S}$ = Daya semu

$\theta=$ Sudut antara tegangan dan arus / beban

\subsection{Simulator Sistem Load Shedding}

Simulator sistem load shedding yang dibuat adalah simulator pemakaian 8 beban yang memiliki daya yang berbeda pada tiap bebannya. Beban tersebut adalah motor 1 sebagai beban 1, motor 2 sebagai beban 2, heater 1 sebagai beban 3, heater 2 sebagai beban 4, solder sebagai beban 5, fan sebagai beban 6,lampu 1 sebagai beban 7, lampu 2 sebagai beban 8 . Selain simulator pemakaian 8 beban dibuat juga indikator genset yang menggunakan 2 fan. Diagram blok dari sistem simulator ini dapat dilihat pada Gambar 1 dan realisasi dari simulator ini dapat dilihat pada Gambar 2.

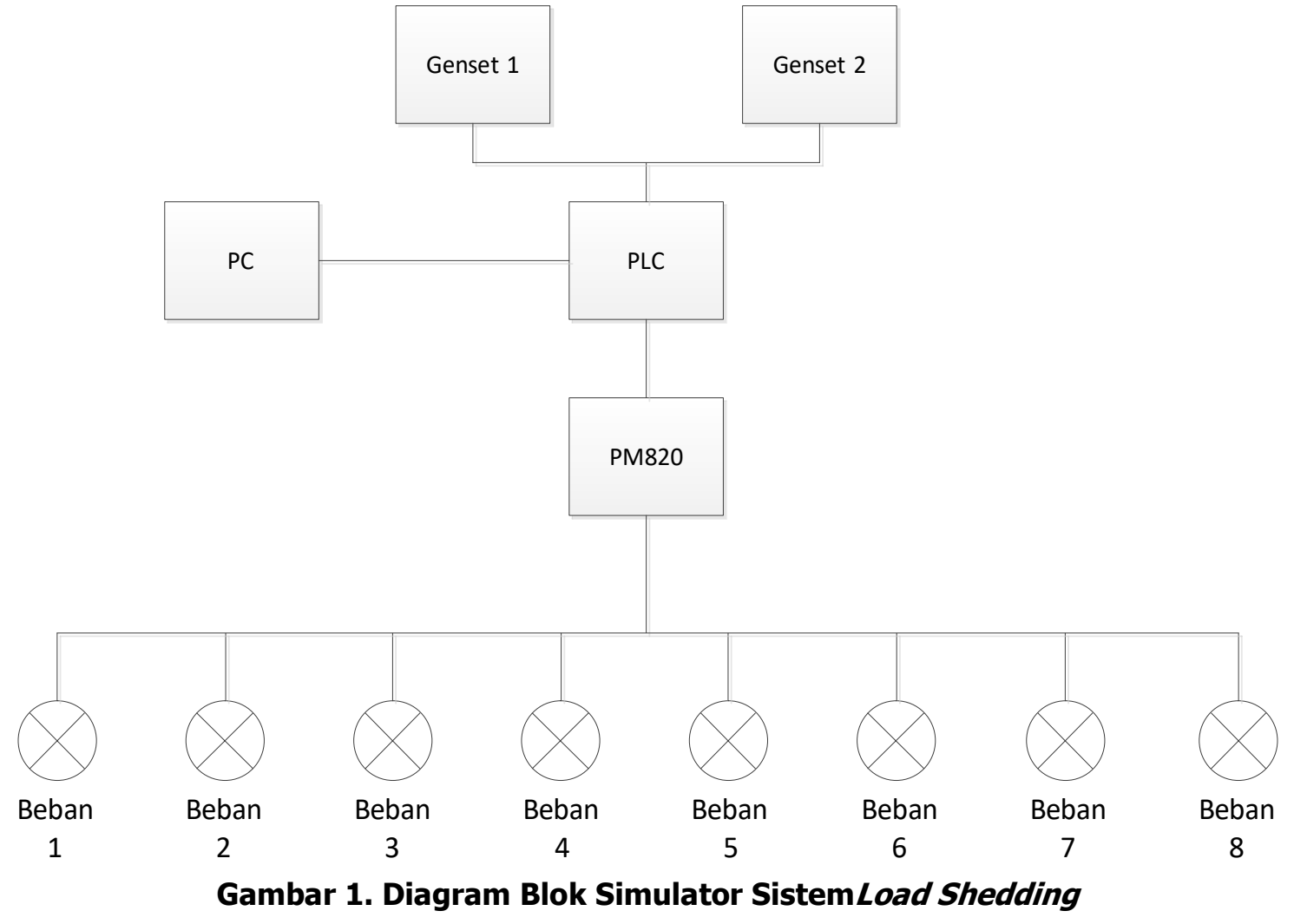




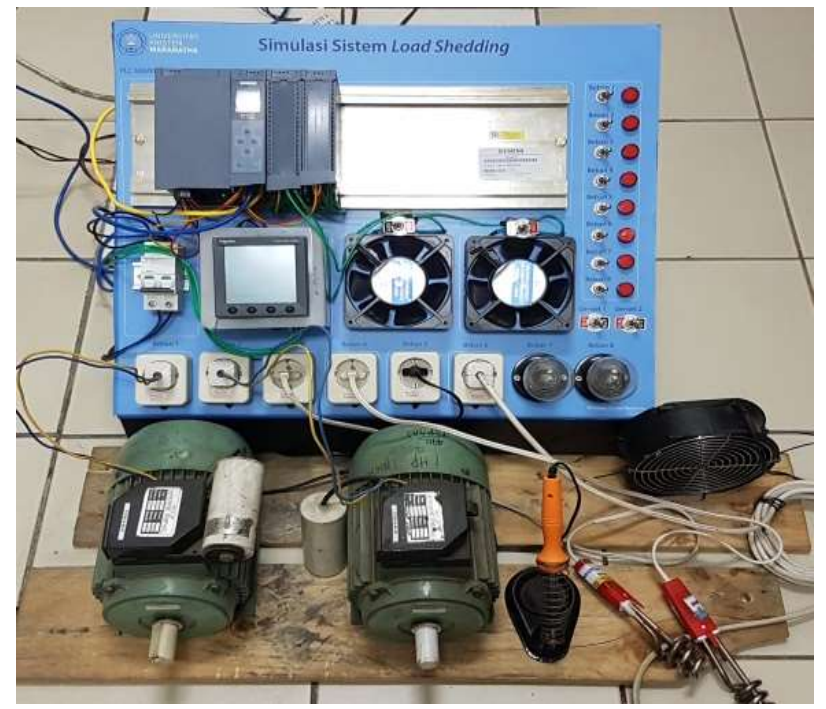

\section{Gambar 2. Realisasi Simulator SistemLoad Shedding}

Power Meter PM820 digunakan untuk membaca keseluruhan daya listrik dan besaran lainnya saat sedang digunakan dan data tersebut dikirim ke PLC, untuk ditampilkan pada SCADA (Nagar \& Mehta, 2018). PLC berfungsi untuk mengaktifkan atau mematikan sistem, mengumpulkan data dari PM820, memprogram keseluruhan sistem, dan juga memberikan perintah tindakan saat terjadi load shedding. PC (komputer) digunakan untuk pemantauan status beban, status genset, dan juga pemantauan keseluruhan daya beban serta besaran listrik lainnya melalui SCADA. Selain itu pada SCADA dapat digunakan juga untuk melihat grafik beban, grafik kapasitas genset, dan juga grafik segitiga daya.

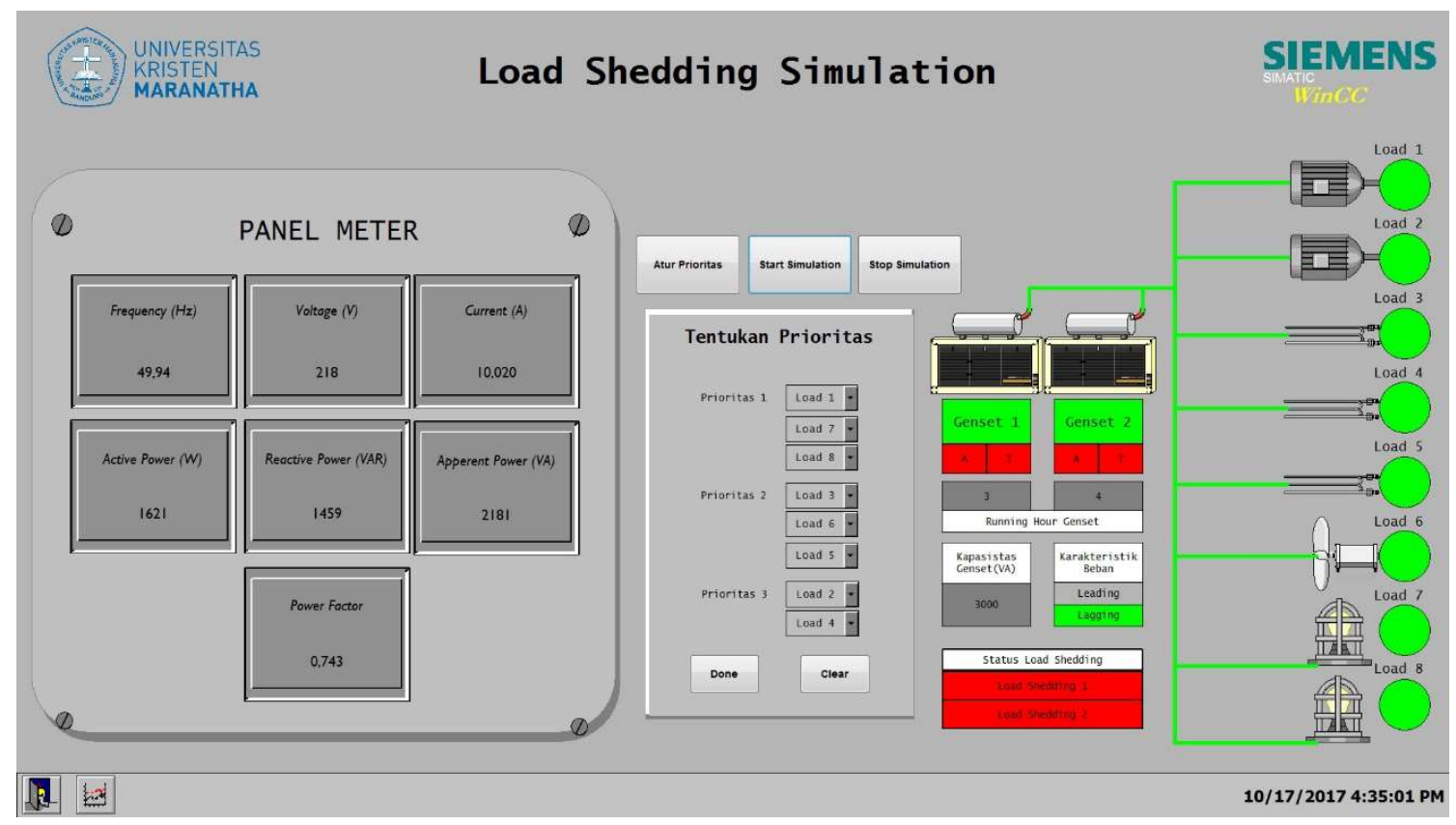

Gambar 3. Desain Tampilan SCADA Simulasi Load Shedding

Gambar 3 adalah desain tampilan dari SCADA simulasi load shedding. Dalam realisasi SCADA tersebut ada 3 tombol yaitu tombol "atur prioritas", "start simulation"dan "stop simulation". 
Tombol "atur prioritas" adalah tombol untuk mengatur prioritas dari 8 beban tersebut. Tombol "start simulation"adalah tombol untuk memulai simulasi, sedangkan tombol "stop simulation" untuk mematikan simulasi. Prioritas pada simulasi dibatasi dibagi menjadi 3 yaitu 3 beban sebagai prioritas utama, 3 beban sebagai prioritas kedua, dan 2 beban sebagai prioritas ketiga. Segitiga daya tidak dinyatakan dalam grafik tetapi dalam nilai yang ditunjukkan pada panel meter dari Load Shedding Simulation.

Pada SCADA warna hijau menunjukkan status aktif dan warna merah menunjukkan status tidak aktif. Pada Gambar 3 jika genset dalam kondisi alarm maka status (A) akan berubah menjadi hijau dan genset akan berkedip antara warna hijau dan kuning. Jika dalam kondisi trip maka status ( $\mathrm{T}$ ) akan berubah menjadi menjadi hijau dan genset akan berubah menjadi merah. Running hour pada akan berubah sesuai dengan lama genset tersebut dalam keadaan aktif, dalam simulasi ini waktu kerja genset selama 1 jam akan diwakili dengan 10 detik pada simulasi. Kapasitas genset menunjukkan daya untuk total kedua genset. Karakteristik beban akan menunjukkan karakteristik keseluruhan dari beban. Sedangkan status load shedding akan menunjukkan status load shedding sesuai dengan kondisinya. Pada sebelah kiri SCADA terdapat panel meter sedang membaca besaran listrik yaitu frekuensi, tegangan, arus, daya nyata, daya reaktif, daya semu dan juga power factor pada kondisi keseluruhan beban aktif. Pada Gambar 3ada tombol "exit" untuk keluar dari SCADA dan tombol "graph" untuk berpindah ke tampilan grafik.
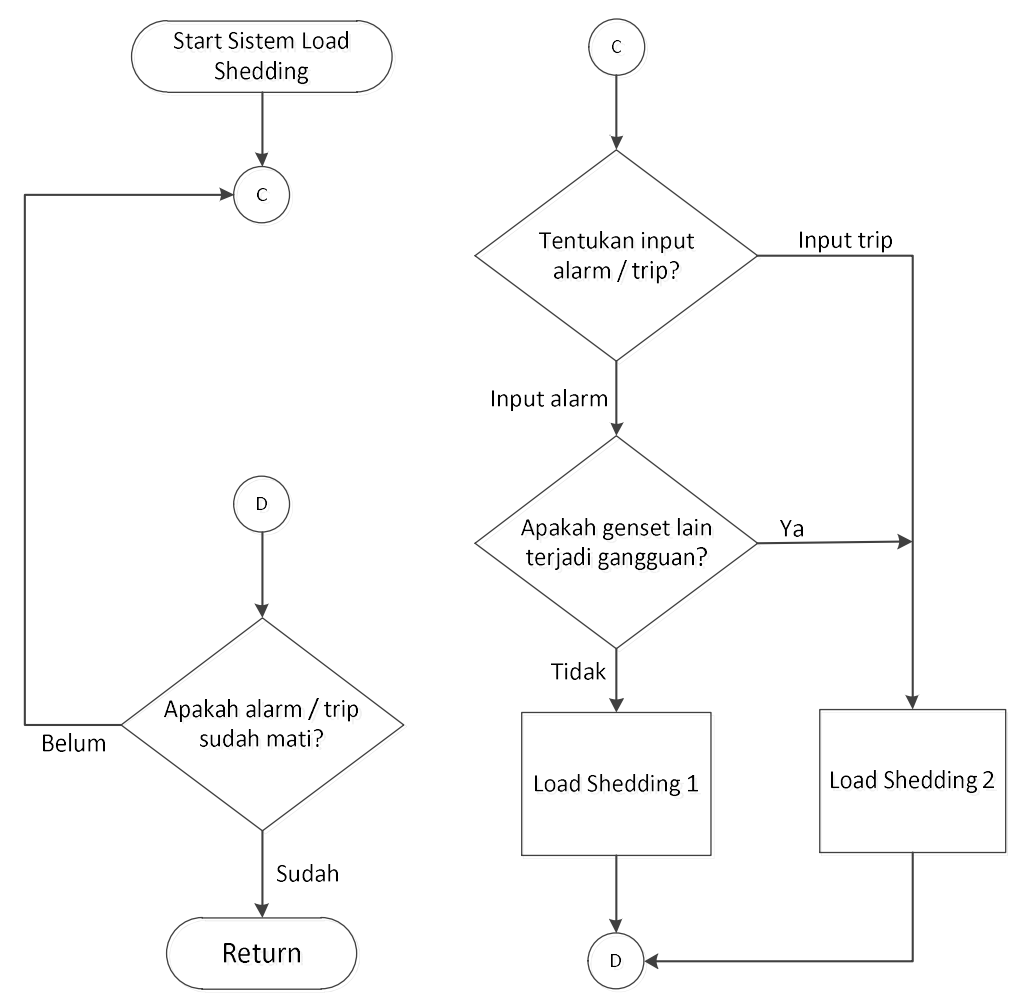

Gambar 4. Diagram Alir Sistem Load Shedding

Sistem load shedding ini akan mulai setelah adanya input alarm / trip yang masuk ke PLC yang dideteksi pada subsistem genset. Tindakan load shedding 1 pada Gambar 4 yaitu sistem akan 
mematikan beban yang paling besar dan bukan beban prioritas utama. Tindakan load shedding 2 yaitu sistem akan mematikan beban secara bertahap dari prioritas yang paling rendah hingga daya beban berada dibawah 1200VA. Saat mulai sistem load shedding ini akan menentukan jenis input terlebih dahulu.

Jika ditentukan bahwa input tersebut adalah input alarm dari salah satu genset, maka sistem akan melakukan pemeriksaan gangguan pada genset yang lainnya. Apabila genset lainnya tidak mengalami gangguan maka akan dilakukan tindakan load shedding 1. Apabila pemeriksaan pada genset lainnya, genset tersebut mengalami gangguan dan jika ditentukan bahwa input tersebut adalah input trip dari salah satu genset maka akan dilakukan tindakan load shedding 2. Sistem load shedding ini akan berhenti apabila input alarm / trip tersebut sudah hilang dan apabila ada input stop dari SCADA. Diagram alir dari sistem load shedding dapat dilihat pada Gambar 4.

\section{HASIL DAN PEMBAHASAN}

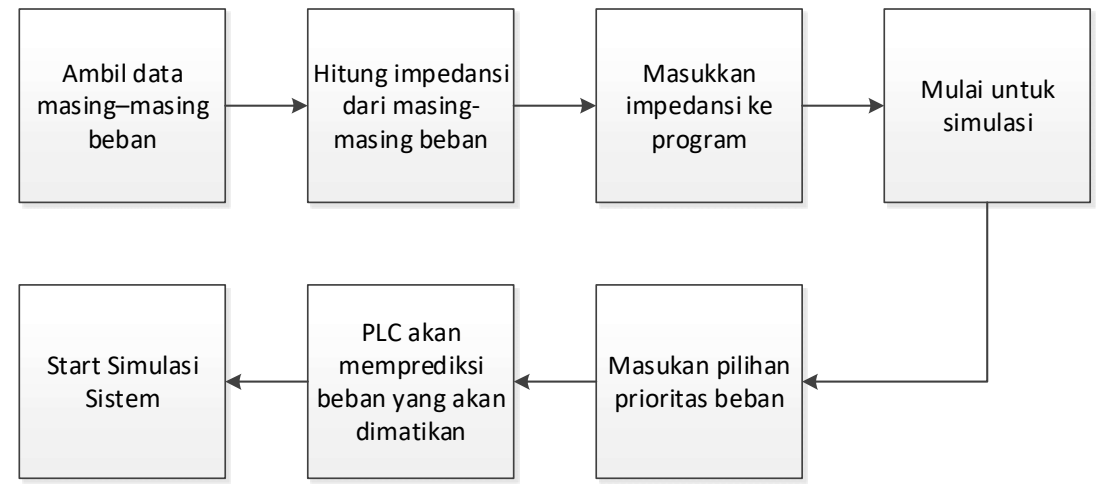

Gambar 5. Langkah - Langkah Uji Coba Simulator Sistem Load Shedding

Tabel 1. Data rata-rata Beban

\begin{tabular}{|c|l|r|r|r|r|r|r|r|}
\hline No. Beban & Nama Beban & $\begin{array}{c}\text { Frekuensi } \\
\mathbf{( H z )}\end{array}$ & $\begin{array}{c}\text { Tegangan } \\
\mathbf{( V )}\end{array}$ & \multicolumn{1}{|c|}{$\begin{array}{c}\text { Arus } \\
\mathbf{( A )}\end{array}$} & $\begin{array}{c}\text { Daya } \\
\text { Nyata } \\
\mathbf{( W )}\end{array}$ & $\begin{array}{c}\text { Daya } \\
\text { Reaktif } \\
(\mathbf{V A R})\end{array}$ & \multicolumn{1}{c|}{$\begin{array}{c}\text { Daya } \\
\text { Semu } \\
(\mathbf{V A})\end{array}$} & PF \\
\hline 1 & Motor 1 & 50.036 & 223.8 & 4.257 & 445.5 & 842.3 & 954.2 & 0.4673 \\
\hline 2 & Motor 2 & 50.001 & 224.9 & 4.655 & 444.3 & 948.1 & 1047.6 & 0.4243 \\
\hline 3 & Heater 1 & 50.001 & 224.9 & 1.555 & 348.9 & -23.9 & 349.7 & 0.998 \\
\hline 4 & Heater 2 & 50.009 & 224.3 & 1.625 & 363.8 & -24.6 & 364.2 & 0.998 \\
\hline 5 & Fan & 50.094 & 226.7 & 0.224 & 38.6 & 33.5 & 51.2 & 0.7563 \\
\hline 6 & Solder & 50.099 & 226.5 & 0.11 & 23 & -10 & 25 & 0.9141 \\
\hline 7 & Lampu 1 & 50.01 & 223.3 & 0.31 & 68.7 & -11.6 & 69.5 & 0.9861 \\
\hline 8 & Lampu 2 & 50.078 & 223.9 & 0.25 & 54.7 & -10.9 & 55.8 & 0.9806 \\
\hline
\end{tabular}

Langkah-Langkah dalam melakukan uji coba pada simulator sistem load shedding ditunjukkan pada Gambar 5. Dalam proses mendapatkan impedansi dari masing-masing beban, dilakukan pengukuran frekuensi, tegangan, arus, daya reaktif, daya semua, dan faktor daya sebanyak 10 kali pengukuran terhadap masing - masing beban dan didapatkan data beban rata-rata dari 
8 beban seperti pada Tabel 1 . Tujuan pengukuran rata-rata beban adalah untuk menghitung impedansi dan sudut masing-masing beban.

Tabel 2. Impedansi masing-masing Beban

\begin{tabular}{|l|r|r|}
\hline \multicolumn{1}{|c|}{ Beban } & Impedansi Z $(\boldsymbol{\Omega})$ & \multicolumn{1}{c|}{ Sudut $\left.\mathbf{(}^{\circ}\right)$} \\
\hline Motor 1 & 52.491 & $(+) 62.173$ \\
\hline Motor 2 & 48.282 & $(+) 64.940$ \\
\hline Heater 1 & 144.638 & $(-) 3.921$ \\
\hline Heater 2 & 138.140 & $(-) 3.872$ \\
\hline Fan & 1003.767 & $(+) 41.298$ \\
\hline Solder & 2052.090 & $(-) 23.676$ \\
\hline Lampu 1 & 717.452 & $(-) 9.652$ \\
\hline Lampu 2 & 898.409 & $(-) 11.235$ \\
\hline
\end{tabular}

Setelah itu dengan menggunakan data rata-rata daya dari masing - masing beban maka diperoleh Z (impedansi) dari Persamaan (4) dan sudut masing - masing beban dari Persamaan (5) yang hasilnya dapat dilihat pada Tabel 2. Data dari Tabel 2 digunakan sebagai database SCADA untuk memprediksi beban yang harus dimatikan saat terjadi load shedding. Simulasi load shedding 1 yaitu saat adanya input alarm dari genset 1, sedangkan Simulasi load shedding 2 ada dua keadaan yaitu keadaan pertama adanya input alarm pada kedua genset dan keadaan kedua adalah genset 1 adanya input alarm dan genset 2 ada input trip.

Tabel 3.Perhitungan Prediksi Daya

\begin{tabular}{|c|c|r|r|}
\hline Prioritas ke- & No. Beban & Daya Per Prioritas (VA) & Daya Total (VA) \\
\hline $1,2,3$ & $1,7,8$ & & 992.377 \\
\hline 4 & 3 & 213.560 & 1205.937 \\
\hline 5 & 6 & 10.618 & 1216.555 \\
\hline 6 & 5 & 49.536 & 1266.091 \\
\hline 7 & 2 & 976.693 & 2242.784 \\
\hline 8 & 4 & 224.327 & 2467.111 \\
\hline
\end{tabular}

Tabel 3 berisi perhitungan prediksi daya yang dilakukan oleh PLC. Dari Tabel 3 dapat diprediksi bahwa saat terjadi/oad shedding 1 akan dimatikan beban dengan prioritas 7 (beban no 2) karena beban tersebut adalah beban yang memiliki daya beban paling besar dan bukan beban prioritas 1, 2 dan 3. Saat terjadi load shedding 2 akan dimatikan beban dengan prioritas 4, 5, 6, 7 dan 8 (yaitu beban no 2, 3, 4, 5, 6 bila diurutkan) karena setelah beban - beban tersebut dimatikan daya beban yang ditanggung oleh sistem berada dibawah $1200 \mathrm{VA}$. 


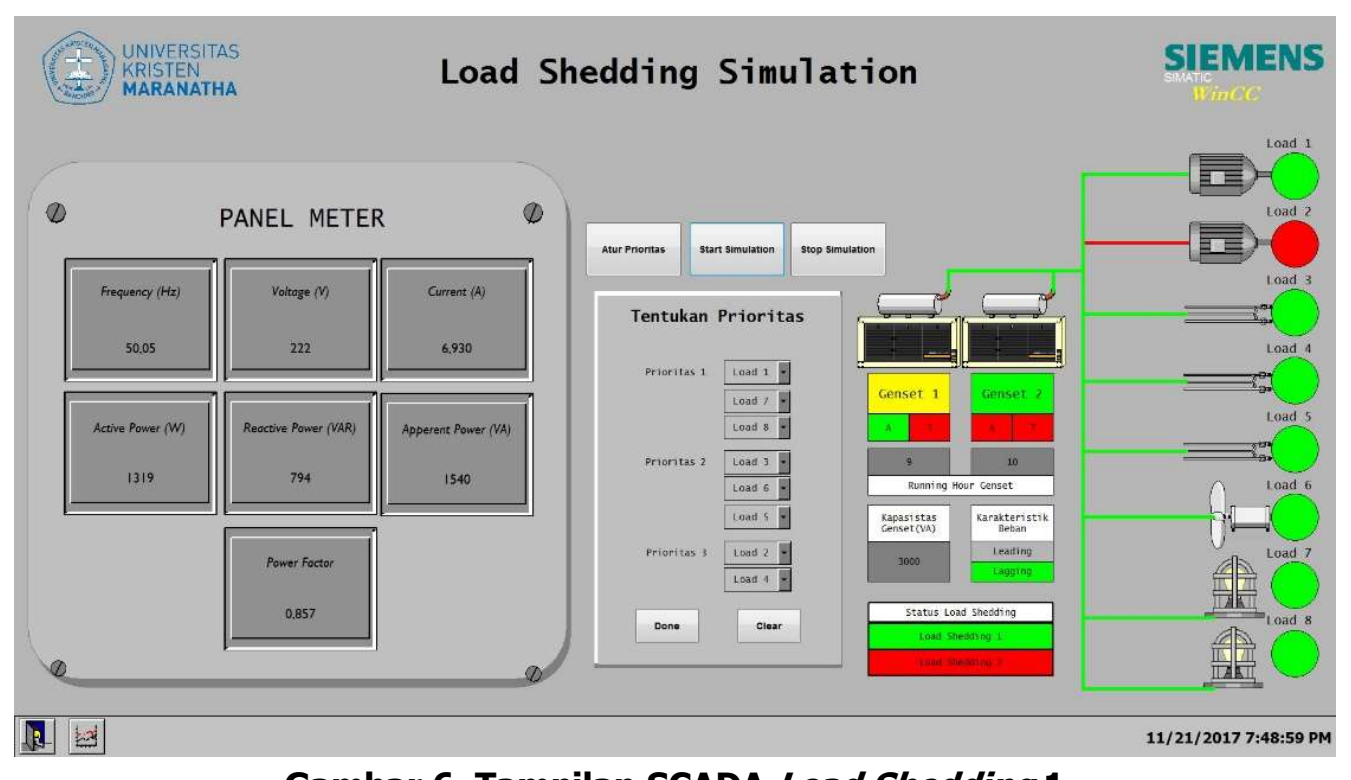

Gambar 6. Tampilan SCADA Load Shedding 1

Gambar 6 adalah tampilan dari SCADA saat terjadi load shedding 1. Indikator beban 2 berubah menjadi warna merah karena beban tersebut dimatikan dari sistem. Indikator genset 1 berkedip warna hijau dan kuning karena genset mengalami alarm dan indikator alarm (A) pada genset 1 berubah warna menjadi hijau. Status load shedding 1 juga berubah warna menjadi hijau karena sedang dalam kondisi load shedding 1 . Hal ini menunjukkan PLC berhasil melakukan prediksi sesuai dengan perhitungan sehingga otomasi yang ditunjukkan sudah sesuai yaitu memutuskan aliran listrik ke beban 2 dan lampu indikator load shedding 1 dihidupkan.

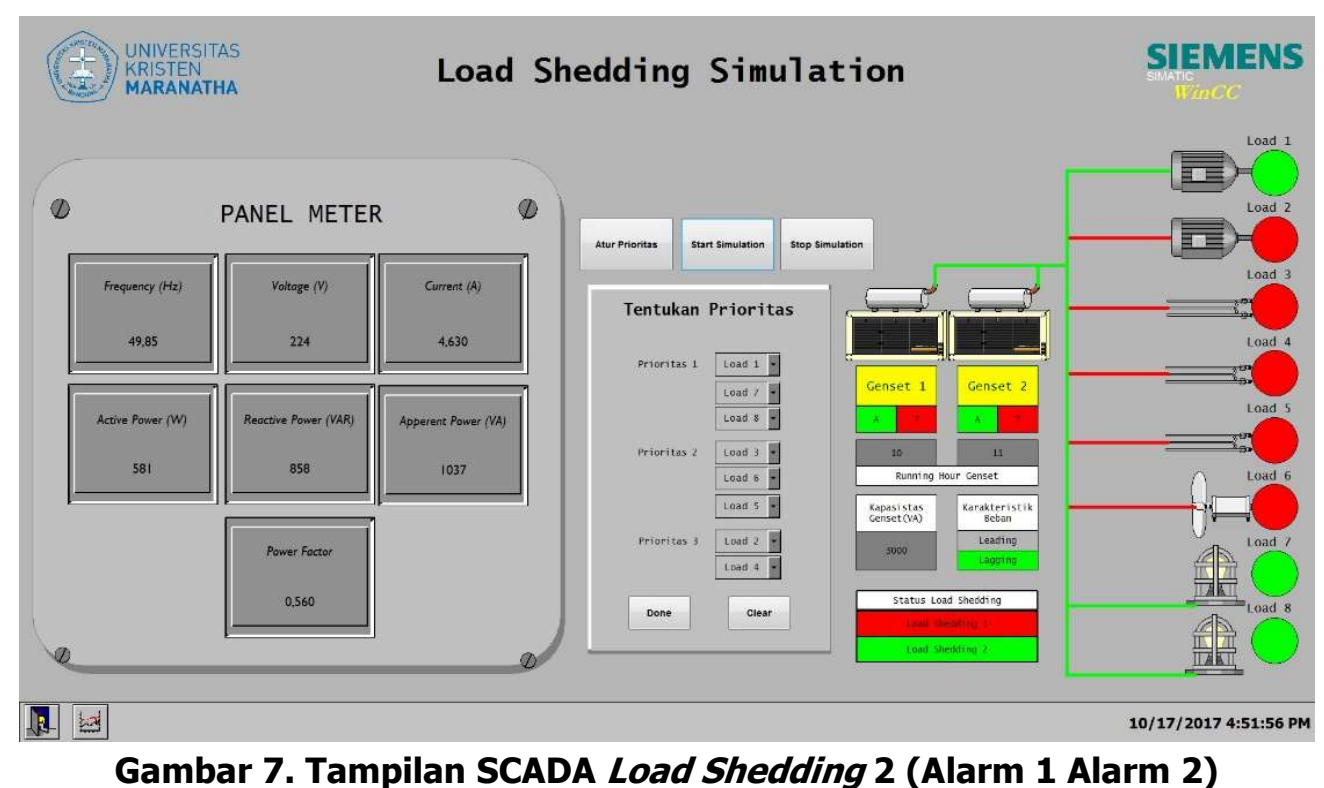

Gambar 7 adalah tampilan dari SCADA saat terjadi load shedding 2 karena terjadi alarm pada genset 1 dan alarm juga pada genset 2. Indikator beban 2, 3, 4, 5 dan 6 berubah menjadi warna merah karena beban tersebut dimatikan dari sistem. Indikator genset 1 dan 2 berkedip 
warna hijau dan kuning karena genset mengalami alarm dan indikator alarm (A) pada genset 1 dan 2 berubah warna menjadi hijau. Status load shedding 2 juga berubah warna menjadi hijau karena sedang dalam kondisi load shedding 2. Hal ini menunjukkan PLC berhasil melakukan prediksi sesuai dengan perhitungan sehingga otomasi yang ditunjukkan sudah sesuai yaitu memutuskan aliran listrik ke beban 2, 3, 4, 5, dan 6 serta lampu indikator load shedding 2 dihidupkan.

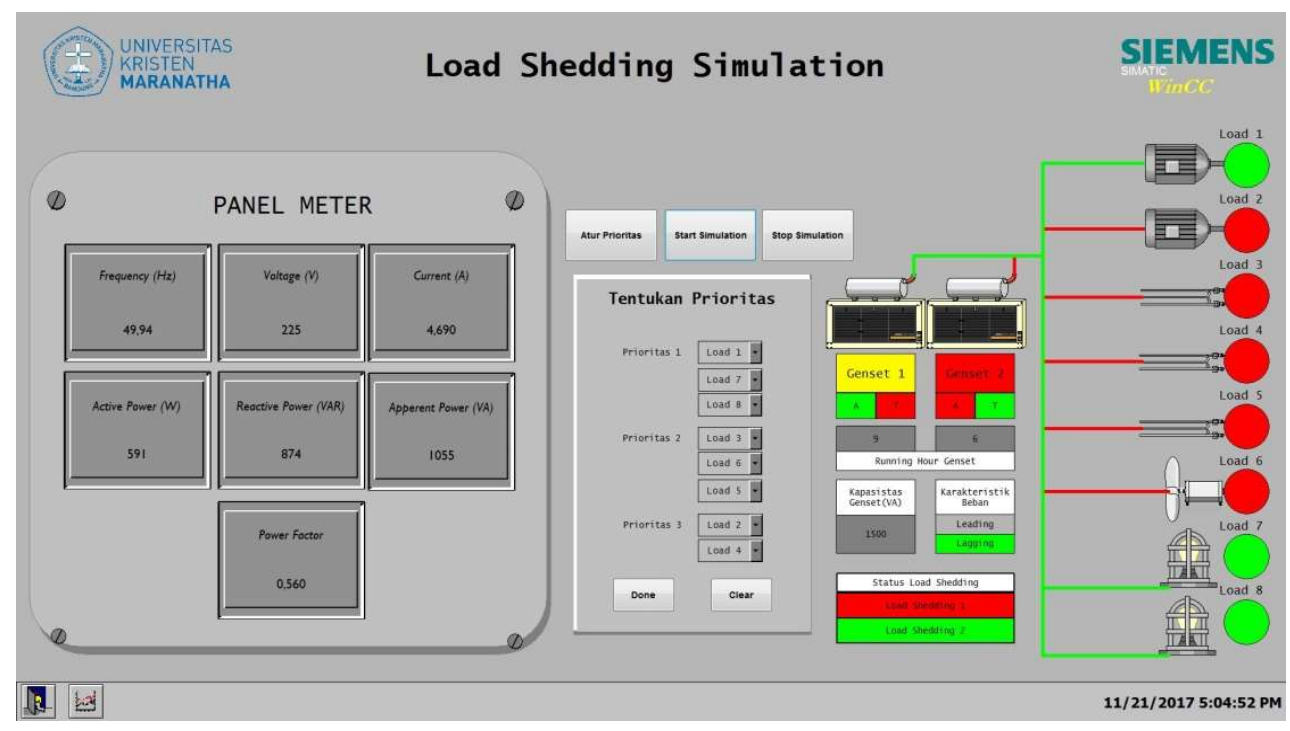

Gambar 8. Tampilan SCADA Saat Load Shedding 2 Keadaan 2 (Alarm 1 Trip 2)

Gambar 8 adalah tampilan dari SCADA saat terjadi load shedding 2 karena terjadi alarm di genset 1 dan trip di genset 2 . Indikator beban 2, 3, 4, 5 dan 6 berubah menjadi warna merah karena beban tersebut dimatikan dari sistem. Indikator genset 1 berkedip warna hijau dan kuning karena genset mengalami alarm dan indikator alarm $(A)$ pada genset 1 berubah warna menjadi hijau. Indikator genset 2 berubah warna menjadi merah karena genset mengalami trip dan indikator trip $(\mathrm{T})$ pada genset 2 berubah warna menjadi hijau. Status load shedding 2 juga berubah warna menjadi hijau karena sedang dalam kondisi load shedding 2. Hal ini menunjukkan PLC berhasil melakukan prediksi sesuai dengan perhitungan sehingga otomasi yang ditunjukkan sudah sesuai yaitu memutuskan aliran listrik ke beban 2, 3, 4, 5, dan 6 serta lampu indikator load shedding 2 dihidupkan.

Tabel 4.Status Beban Simulasi Load Shedding

\begin{tabular}{|c|c|c|c|}
\hline \multirow{2}{*}{ Beban } & \multicolumn{3}{|c|}{ Status beban saat } \\
\cline { 2 - 4 } & \multirow{2}{*}{ Load Shedding 1 } & \multicolumn{2}{|c|}{ Load Shedding 2 } \\
\cline { 2 - 4 } & & Alarm 1 Trip 2 & Alarm 1 Alarm 2 \\
\hline 1 & ON & ON & ON \\
\hline 2 & OFF & OFF & OFF \\
\hline 3 & ON & OFF & OFF \\
\hline 4 & ON & OFF & OFF \\
\hline 5 & ON & OFF & OFF \\
\hline 6 & ON & ON & ON \\
\hline 7 & ON & ON & ON \\
\hline 8 & ON & & \\
\hline
\end{tabular}


Tabel 4 adalah tabel keadaan beban setelah mengalami load shedding tahap 1, load shedding tahap 2 dengan kondisi 1 dan load shedding tahap 2 dengan kondisi 2 . Pada saat load shedding 1 beban yang mati adalah beban 2. Pada load shedding tahap 2 dalam keadaan 1 maupun keadaan 2 akan dimatikan beban 2, 3, 4, 5 dan 6 untuk simulasi pertama. Hasil ini menunjukkan bahwa PLC secara otomatis telah berhasil melakukan perhitungan dan prediksi.

Tabel 5 Besaran Listrik Simulasi Load Shedding

\begin{tabular}{|l|r|r|r|}
\hline \multirow{2}{*}{ Besaran Listrik } & \multirow{2}{*}{ Load Shedding 1 } & \multicolumn{2}{c|}{ Load Shedding 2 } \\
\cline { 3 - 4 } & & Alarm 1 Trip 2 & Alarm 1 Alarm 2 \\
\hline Frekuensi (Hz) & 49.99 & 49.94 & 49.85 \\
\hline Tegangan (V) & 222 & 225 & 224 \\
\hline Arus (A) & 6.93 & 4.69 & 4.63 \\
\hline Daya nyata (W) & 1319 & 591 & 581 \\
\hline Daya reaktif (VAR) & 794 & 874 & 858 \\
\hline Daya semu (VA) & 1540 & 1055 & 1037 \\
\hline Power faktor & 0.857 & 0.560 & 0.560 \\
\hline
\end{tabular}

Tabel 5 adalah tabel besaran listrik beban setelah mengalami load shedding 1, load shedding 2 (alarm 1 trip 2) dan load shedding 2 (alarm 1 alarm 2). Pada saat load shedding 1 beban yang mati adalah beban 2 karena beban 2 bukanlah beban prioritas utama dan memiliki daya beban paling besar. Setelah dilakukan load shedding tahap 1 daya beban berkurang menjadi 1540VA. Pada load shedding tahap 2 dalam keadaan 1 maupun keadaan 2 akan dimatikan beban 2, 3, 4, 5 dan 6 . Setelah dilakukan load shedding tahap 2, untuk simulasi load shedding 2 keadaan pertama daya beban berkurang menjadi 1037VA dan keadaan kedua daya beban berkurang menjadi 1055VA. Keadaan kedua daya beban seharusnya sama, perbedaan kemungkinan disebabkan pembacaan saat data diambil beban masih belum steady.

Tabel 6. Perhitungan Prediksi Daya Simulasi Load Shedding Kedua
\begin{tabular}{|c|c|r|r|}
\hline Prioritas & Beban & Daya Per Prioritas (VA) & Daya Total (VA) \\
\hline $1,2,3$ & $8,6,1$ & & 977.008 \\
\hline 4 & 3 & 206.287 & 1183.294 \\
\hline 5 & 4 & 274.522 & 1457.816 \\
\hline 6 & 7 & 52.921 & 1510.736 \\
\hline 7 & 5 & 49.174 & 1559.910 \\
\hline 8 & 2 & 929.376 & 2489.286 \\
\hline
\end{tabular}

Percobaan simulasi kedua dengan cara yang sama dilakukan dan prioritas beban diubah.Tabel 6 berisi perhitungan prediksi daya yang dilakukan oleh PLC. Dari Tabel 6 dapat diprediksi bahwa saat load shedding 1 akan dimatikan beban dengan prioritas 8 karena beban tersebut adalah beban yang memiliki daya beban paling besar dan bukan beban prioritas 1, 2 dan 3 . Saat terjadi load shedding 2 akan dimatikan beban dengan prioritas 5, 6, 7 dan 8 (beban no 2, 4, 5, 7 bila diurutkan) karena jika beban - beban tersebut dimatikan daya beban yang ditanggung oleh sistem berada dibawah 1200VA. 
Tabel 7. Status Beban Simulasi Load Shedding Kedua

\begin{tabular}{|c|c|c|c|}
\hline \multirow{2}{*}{ Beban } & \multicolumn{3}{|c|}{ Status beban saat } \\
\cline { 2 - 4 } & \multirow{2}{*}{ Load Shedding 1 } & \multicolumn{2}{|c|}{ Load Shedding 2 } \\
\cline { 3 - 4 } & & Alarm 1 Trip 2 & Alarm 1 Alarm 2 \\
\hline 1 & ON & ON & ON \\
\hline 2 & OFF & OFF & OFF \\
\hline 3 & ON & OFF & ON \\
\hline 4 & ON & OFF & OFF \\
\hline 5 & ON & ON & ON \\
\hline 6 & ON & OFF & OFF \\
\hline 7 & ON & ON & ON \\
\hline 8 & ON & \multicolumn{2}{c}{} \\
\hline
\end{tabular}

Tabel 7 adalah tabel keadaan beban setelah mengalami load shedding 1, load shedding 2 dengan kondisi 1 dan load shedding tahap 2 dengan kondisi 2. Pada saat load shedding 1 beban yang mati adalah beban 2. Pada load shedding tahap 2 dalam keadaan 1 maupun keadaan 2 dimatikan beban 2, 4, 5 dan 7 untuk simulasi kedua. Hasil ini menunjukkan bahwa PLC secara otomatis telah berhasil melakukan perhitungan dan prediksi.

Tabel 8. Perhitungan Prediksi Daya Simulasi Ketiga

\begin{tabular}{|c|c|r|r|}
\hline Prioritas ke- & Beban & Daya Per Prioritas (VA) & Daya Total (VA) \\
\hline $1,2,3$ & $3,6,8$ & & 421.811 \\
\hline 4 & 2 & 812.820 & 1234.630 \\
\hline 5 & 1 & 926.588 & 2161.219 \\
\hline 6 & 7 & 32.827 & 2194.046 \\
\hline 7 & 4 & 223.609 & 2417.655 \\
\hline 8 & 5 & 49.455 & 2467.110 \\
\hline
\end{tabular}

Percobaan simulasi ketiga dengan cara yang sama dilakukan dan prioritas beban diubah lagi. Tabel 8 berisi perhitungan prediksi daya yang dilakukan oleh PLC. Dari tabel tersebut dapat diprediksi bahwa saat load shedding 1 akan dimatikan beban dengan prioritas 5 karena beban tersebut adalah beban yang memiliki daya beban paling besar dan bukan beban prioritas 1,2 dan 3. Saat terjadi load shedding 2 akan dimatikan beban dengan prioritas 4, 5, 6, 7 dan 8 (no beban 1, 2, 4, 5, 7 bila diurutkan) karena setelah beban - beban tersebut dimatikan daya beban yang ditanggung oleh sistem berada dibawah 1200VA.

Tabel 9 adalah tabel keadaan beban setelah mengalami load shedding tahap 1, load shedding tahap 2 dengan kondisi 1 dan load shedding tahap 2 dengan kondisi 2. Pada saat load shedding 1 beban yang mati adalah beban 1 . Pada load shedding tahap 2 dalam keadaan 1 maupun keadaan 2 akan dimatikan beban 1, 2, 4, 5 dan 7 untuk simulasi ketiga. Hasil ini menunjukkan bahwa PLC secara otomatis telah berhasil melakukan perhitungan dan prediksi. 
Tabel 9. Status Beban Simulasi Load Shedding Ketiga

\begin{tabular}{|c|c|c|c|}
\hline \multirow{2}{*}{ Beban } & \multicolumn{3}{|c|}{ Status beban saat } \\
\cline { 2 - 4 } & Load Shedding & \multicolumn{2}{|c|}{ Load Shedding 2 } \\
\cline { 2 - 4 } & $\mathbf{1}$ & Alarm 1 Trip 2 & Alarm 1 Alarm 2 \\
\hline 1 & OFF & OFF & OFF \\
\hline 2 & ON & OFF & OFF \\
\hline 3 & ON & ON & ON \\
\hline 4 & ON & OFF & OFF \\
\hline 5 & ON & OFF & OFF \\
\hline 6 & ON & ON & ON \\
\hline 7 & ON & OFF & OFF \\
\hline 8 & ON & ON & ON \\
\hline
\end{tabular}

Tabel 10. Daya Prediksi dan Daya Pengukuran

\begin{tabular}{|c|c|c|c|c|c|r|}
\hline \multirow{3}{*}{ Simulasi } & \multicolumn{7}{|c|}{ Daya Semu Keseluruhan Beban (VA) } \\
\cline { 2 - 7 } & LS1 & LS1 & LS2 (1) & LS2 (1) & LS2 (2) & LS2 (2) \\
\cline { 2 - 7 } & Prediksi & $\begin{array}{c}\text { Percoba } \\
\text { an }\end{array}$ & Prediksi & $\begin{array}{c}\text { Percoba } \\
\text { an }\end{array}$ & Prediksi & $\begin{array}{c}\text { Percoba } \\
\text { an }\end{array}$ \\
\hline 1 & 1490.418 & 1540 & 992.377 & 1037 & 992.377 & 1055 \\
\hline 2 & 1559.910 & 1670 & 977.008 & 1162 & 977.008 & 1175 \\
\hline 3 & 1540.522 & 1488 & 421.811 & 437 & 421.811 & 436 \\
\hline Error (\%) & \multicolumn{7}{|c|}{1.46} & & 2.57 \\
\hline
\end{tabular}

Tabel 10 berisikan data perbandingan daya semu yang diprediksi oleh PLC dan daya semu yang terukur setelah simulasi load shedding 1, load shedding 2 dengan keadaan 1, dan load shedding 2 dengan keadaan 2 . Error rata-rata dari ketiga simulasi antara daya yang diprediksi oleh PLC dan daya terukur untuk simulasi load shedding 1 adalah $2.28 \%$, sedangkan untuk simulasi load shedding 2 keadaan 1 adalah $1.46 \%$, dan untuk simulasi load shedding 2 keadaan 2 adalah 2.57\%. Terdapat perbedaan daya prediksi dari perhitungan (teori) dengan hasil pengukuran daya secara langsung menggunakan Power Meter PM820, hal ini kemungkinan disebabkan pembacaan saat data diambil beban masih belum steady.

\section{KESIMPULAN}

Otomasi pada simulator sistem load shedding berhasil direalisasikan dan berfungsi sesuai yang diinginkan. Melalui otomasi pada simulator tersebut, sistem berhasil melepaskan beban terbesar yang bukan prioritas utamapada simulasi load shedding tahap 1 . Sistem juga berhasil melepaskan beban secara bertahap hingga daya beban tersebut dibawah 1200VA pada simulasi load shedding tahap 2. Sistem load shedding yang direalisasi berhasil dilakukan melalui perhitungan yang dilakukan di Programmable Logic Controller (PLC) untuk memprediksi beban yang akan dilepaskan. Pengujian dilakukan pada masing-masing load shedding (tahap 1 dan tahap 2) sebanyak tiga kali dan hasilnya sesuai dengan yang diinginkan. Terdapat perbedaan hasil dari data daya yang diprediksi oleh PLC (melalui perhitungan/teori) dan daya terukur untuk simulasi load shedding 1 adalah $2.28 \%$, sedangkan untuk simulasi load shedding 2 keadaan 1 adalah 1.46\%, dan untuk simulasi load shedding 2 
keadaan 2 adalah $2.57 \%$. Perbedaan ini kemungkinan disebabkan pembacaan saat data diambil beban masih belum steady.

\section{DAFTAR RUJUKAN}

Agus Putranto, Abdul Mukti, Djoko Sugiono, Syaiful Karim, Arie Eric Rawung, Sodikin Susa'at, S. (2008). Tenik Otomasi Industri untuk Sekolah Menengah Kejuruan, 1-8.

Belly, A., Agusman, C., \& Lukman, B. (2010). Daya aktif, reaktif \& nyata, 3-5.

Guan, L., \& Wang, X. (2016). Impacts of Island Load Shedding and Restoration Strategies on Reliability of Microgrid in Distribution System. 2006 Canadian Conference on Electrical and Computer Engineering, (1201431123), 1594-1598.

Gusaebi. (2014). Pelepasan Beban Berdasarkan Tipe Beban, 1-2.

Keles, C., Alagoz, B. B., \& Kaygusuz, A. (2015). A Note On Demand Side Load Management by Maximum Power Limited Load Shedding Algorithm For Smart Grids. In 2015 3rd International Istanbul Smart Grid Congress and Fair (ICSG) (pp. 1-5).

Nagar, A., \& Mehta, S. (2018). Steam turbine lube oil system protections using SCADA \& PLC. Proceedings of the 2017 International Conference on Intelligent Computing and Control Systems, ICICCS 2017, 2018-Janua, 1376-1381. https://doi.org/10.1109/ICCONS.2017.8250695

Nugraheni, A., \& Setiabudy, R. (2014). Frekuensi Pada Sistem Tenaga Listrik Cnooc Ses Ltd. Teknik Elektro, 2(4), 1-7.

Sartika, E. M., \& Indra Maulidin, T. A. P. (2018). Perancangan dan Realisasi Alat Demonstrasi PC-based Control untuk Simulasi Keamanan Bangunan menggunakan Embedded PC. Sistem Kendali-Tenaga-Elektronika-Telekomunikasi-Komputer, ス1), 46-59.

Wahyudi, W., Rahman, A., \& Nawawi, M. (2018). Perbandingan Nilai Ukur Sensor Load Cell pada Alat Penyortir Buah Otomatis terhadap Timbangan Manual. ELKOMIKA: Jurnal Teknik Energi Elektrik, Teknik Telekomunikasi, \& Teknik Elektronika, 5(2), 207. doi: https://doi.org/10.26760/elkomika.v5i2.207

Wang, Z., Guo, L., Wu, K., Liu, W., \& Zhou, J. (2014). Minimum Load-Shedding Calculation Approach Considering Loads Difference. 2014 IEEE Innovative Smart Grid Technologies - Asia (ISGT ASIA), 2(6), 344-348.

Ye, L. I., Baohui, Z., \& Member, S. (2014). A New Adaptive Load Shedding Control Strategy Based on the Transient Voltage Disturbance Scale Detection in Power Systems. In 2014 14th International Conference on Environment and Electrical Engineering (pp. 408413). 